\title{
European Creative Industry Strategies: The Dawn of a New Public Policy
}

\author{
Emese Pupek
}

\begin{abstract}
Creative industries have an increasingly significant role in societies and economies. Numerous countries expect this particular branch of the industry to help foster economic and social development. To what extent is it possible for the public sphere to respond to the demands of creative industries? Has the public sphere realized and started deploying the possibilities of creative industries? Do relevant political decisions exist? This paper aims at discovering characteristic features related to the political commitment of individual countries. The starting-point is to research cultural policies, assuming that creative industries are in a very close connection with that particular policy field.

The study is based on so-called COMPENDIUM country profiles of 42 countries. The COMPENDIUM is a continually updated web-basedinformation and monitoring system focusing on the cultural policies and trends of European nations under the auspices of the ERIC arts of the Council of Europe since 1998.
\end{abstract}

Index Terms-Creative industries, creative strategies, cultural policies, ICT, public policy.

\section{Cultural Policy as a Starting-Point}

The origins of cultural policy is traditionally traced back to the French revolution, when the consumption of culture was opened up for the broader public extending the previous elite audience and making cultural products available for everyone. The state has always been decisive in this process, but its role has undergone significant changes.

In the 19th century the primary objective of each state was to preserve cultural heritage, they established and maintained museums, operated and developed libraries and contributed to the functioning of galleries. Later, cultural policy became closely linked to the process of democratization bringing about profound social influences including for example the idea of individual personal fulfilment, the freedom of expression and the preservation of diversity. The functions of cultural policy started to multiply with a stronger focus on the issue of economic sustainability and the intention of establishing proper working conditions for artists and cultural workers. Finally, the creative workers entered the scene at the end of the 20th century and in the early $21 \mathrm{st}$ century.

In 1997 the Labour Government of the United Kingdom listed the following 13 sectors as part of the creative industries: advertising, architecture, arts, computer games/entertainment software, crafts, design, fashion, film and video, music, performing arts, publishing, software,

Manuscript received July 29, 2014; revised November 30, 2014.

Emese Pupek is with the BKF University of Applied Sciences, Budapest, Hungary (e-mail:pupek.emese@oh.gov.hu). television and radio. But where is the border between culture and creative industries? Does that border exist at all?

Nations rarely record the definition of culture in strategic documents or in legal provisions. However, there are some exceptions, for instance, the constitutions of Azerbaijan, Belgium or Estonia all make references to their concept of culture [1]. In defining culture, nations use a definition based on the one specified by UNESCO in its introduction to the Universal Declaration on Cultural Diversity (2007) denoting the spiritual, material, intellectual and emotional features of society or a social group; and that it encompasses, in addition to art and literature, lifestyles, ways of living together, value systems, traditions and beliefs.

The definition of culture also has a spiritual and a functional interpretation. According to the spiritual or more elevated definition, culture includes everything that has been created by our civilization or everything that has been developed and perfected by humans using their physical and intellectual abilities. The Holy See, Liechtenstein, Moldova, Armenia, Russia and San Marino use the above version for their definition [1]. Those in favour of the functional definition list the following fields under the category of culture: science, research, education, history, religion and government policies, the operation of institutions (libraries, museums and archives), cultural heritage, freedom of creation and social participation in cultural events.

A lot of countries do not simply identify culture with arts. The concept of culture for these countries also include lifestyle, human rights, values, traditions and beliefs. These countries (Austria, Bulgaria, Finland, France, Greece, Georgia, Croatia, Poland, Germany, Italy, Armenia, Slovenia, the Holy See) focus on the role of culture in establishing values, creating and preserving traditions and formulating identities [1]. The protection and development of language through culture usually constitutes part of their explanation of culture, in addition to behaviour and clothing. Culture gives behavioural patterns both to the next generation and immigrants, it transmits information among generations and connects nations. Thus, culture has a crucial role in strengthening social cohesion, building international relations, it helps us appreciate each other, it promotes socialization and the integration of the individual into society. Culture contributes to the development of each citizen intellectually, emotionally and morally.

In formulating their definition of culture, individual nations mentioned other sectors and institutions as well, such as education, research, cultural heritage, tourism and libraries, museums, archives, galleries and monuments. On the other hand, instead of giving a definition of culture, numerous countries chose to simply list several arts, mostly the following: architecture, music, performing arts, literature, 
visual arts, film, audio-visual arts, new media, printing, opera, circus, dance etc.

According to the Czech Republic, France, Poland, Lithuania, Malta, Romania and Switzerland, culture and creativity are the essential sources of the development of both the state and the economy [1]. The creative sector appears in the cultural definitions of Finland, Hungary, Spain and Sweden [1]. There are several other countries that also mention creativity but they use it in a different way, i.e. denoting the unfolding of the arts instead of creative industries.

Cultural industries and creative industries are often used as synonyms, but with a difference in meaning. Art and culture are the main elements in creative industries, creative economies and knowledge-intensive businesses with technical changes (worldwide web, new technologies etc.) also playing a crucial role in them [2]. Creative industries are based on information, knowledge, the communication sector; they are nurtured by culture, they create new products and services offering a final product in the form of intellectual properties. The creative industries are copyright industries.

According to the prognosis of the Pricewaterhouse Coopers Global Entertainment and Media Outlook, the value and the revenues of creative industries are increasing [3]. The creation, distribution, spread, consumption and trade of cultural goods are expanding. 60 years ago the expression of "cultural industry" was used, then in the 1980s it changed to "cultural industries" that covers a more complex structure and dynamism as well as the use of technical and communications tools and a market model [4]. Products and culture became linked together. This kind of change also had an impact on the local level with local authorities realizing that creative industries stimulated the economy. Finally, small and medium-sized enterprises conquered this sphere. Creative industries are establishing new and novel workplaces and represent a new impetus [5].

\section{Creative Industry Policies AND Programmes}

Creative industries play a pioneer role in knowledge-based economies and societies. Recognizing that fact, countries have undertaken to analyse the sector by conducting studies by government order (Czech Republic, Estonia, FRY of Macedonia, Portugal), working out strategies for creative industries (Finland, Malta, Romania, Spain, Sweden, Serbia) and in some cases even integrating these plans into government programmes (Austria, Lithuania, United Kingdom) [1].

The first Finnish national creative strategy was set up as early as 2004 in cooperation with the representatives of civil society, the research and business community. Since art and culture influence economic growth, the main strategic objective set by Finland is to place the country among the top 10 states in the global ranking list on creativity and intellectual competence until 2020. With a view to achieving that aim, Finland primarily emphasizes the role and strength of cultural competencies [1].

The Malta Vision 2015 is best summarized by its motto: "Let our country be the country of creativity!" In 2010 Serbia declared that creative industries should be developed and thus was born the Creative Serbia 2020 programme which underlined the need for research in this field, heightened public awareness of creative industries in cities and specified various - not only financial - types of support for the creative industries [1].

Although not every country has such a grand vision and concrete documents about creative industries, the attitudes of the analysed countries are similar in acknowledging the significant potential of cultural and creative industries and their contribution to the development of the economic and social life of a country. In these countries, however, the process is still in its infancy. In addition to the prevailing problems due to insufficiencies in funding and the administration system, they typically refer to the lack of technology and well-qualified workers as the obstacles hindering smashing success in this field.

The development of entrepreneurial knowledge and skills in the cultural sphere is also frequently outlined in the strategies as a crucial factor. In 2007 Romania approved the National Development Plan for the Cultural Sector which tends to occupy an increasing role in the economic part of the cultural sector. The strategic document of Latvia for the period of 2006-2013 lays down that creative industries produce, develop, use, disseminate, exhibit and preserve economic, cultural and/or entertainment products through which creative industries promote welfare and establish new workplaces. Therefore, entrepreneurship is a priority in the field of creative industry in Latvia. Norway pays increasing attention to the economic possibilities offered by culture. In 2007 the Norwegian Ministry of Trade and Industry launched a plan about the cooperation of culture and business. In Denmark a stronger cooperation between traditional industries and culture is encouraged to improve business skills and inspire traditional industries to use artistic products and abilities in the course of developing their products and services. The Lithuanian government programme for the period of 2008-2012 also included the creative industries with the aim of increasing the share of cultural industries in GDP, elaborating the potential ways of their development through the integration of art, science, training and business universities; strengthening their infrastructure and stimulating investments in this particular field (increasing financial support) [1].

Internationalisation and the global spread of national values are crucial factors in cultural policies due to their potential positive effect on strengthening national unity [6]. Internationalisation appears primarily as an economic factor in the field of creative industries. The establishment of international relations and presence in the international sphere promote cooperation and develop both society and the economy. Creative industries are founded on national cultural values but become fully accomplished under global circumstances. Among the examined countries, Denmark, Finland, the Czech Republic and Latvia have a strategy for creative industries in which internationalisation is a dominant factor. The overall goal of Denmark is to establish international relations in the field of creative industries including participation in international networks. Finland, the Czech Republic and Latvia are committed to supporting the export of creative products and services. Finland has a 
detailed strategy and the Finnish Ministry for Education and Culture has been supporting the internalisation of the creative industries and entrepreneurship since 2007 using EU grants. The most important EU project was the "National programme for promoting the growth and internationalisation of the entrepreneurial activities in creative industries" from 2008 to 2013 with an ESF-allocation of 14.6 million euros. In the Czech Republic, under the aegis of the Design for Export programme, experts provide assistance to Czech creators to participate in exhibitions and fairs abroad [1].

Macedonia gives priority to design which is a rapidly growing subsector of the creative industries and generally it is divided into three parts: industrial, interior and graphic design. 2007 was the Year of Design in Estonia with the Estonian Design Centre being established the following year. The Latvian Ministry of Culture devotes special attention to design and the audio-visual media/multimedia sector within the creative industries due to their export potential. The audio-visual sector has a similar same role in Spain where cinematography is given extra support aiming at the dissemination of Spanish films internationally [1].

However, states do not only support internationalisation. In most cases, it is primarily cinematography that receives support within the creative sector. The state support of cinematography is neither new nor surprising since it is is an expensive industry and as a result of the small national market and language difficulties it cannot work under pure market conditions without state support. In this respect, it isworth taking note of those countries which pay particular attention to this field for certain reasons. For instance, in Ukraine the state gave multiple support to this sector in 2012 (145.9 million UAH) compared to 2006 (20.4 million UAH) and also made relevant taxation rules more favourable. The state support of cinematography is also significant in Austria, Bulgaria, Greece, Poland, Latvia, Lithuania, Moldova, Monaco, Norway, Russia and Sweden [1].

As we can see from the above, cinematography receives the largest share of the state support which is primarily aimed at internationalisation. However, state support is also allocated for the increase of economic potential which is facilitated through incubators, clusters and SMEs.

Within the framework of a special EU programme with a budget of 2.4 million euros, Latvia has established an incubator for creative industry businesses in Riga. Portugal also supports incubators established in the field of creative industries in addition to the creative clusters working in its northern region. Russia pays special attention to the creation of clusters within the creative industries. The first creative cluster was established in 2000 in Moscow (Winzavod Moscow Centre for Contemporary Art), and soon other actors followed suit (ARTPLAY Design Centre, Loft Project ETAGI Saint Petersburg). Spain considers clusters to be a challenge for creative industries, the cornerstone of regional development and the source of economic growth, and since clusters offer favourable circumstances for the use of new information and communications technologies, the state budget supports the spread of ICTs. Spain has realized that SMEs have a significant role in the field of creative industries and that they need capital for modernization, innovation and technological development. Thus, Spain supports SMEs to be able to increase legal content on the Internet and to gain extra resources. Finland, Spain and Germany all work to improve prevailing circumstances through offering cheap loans, taxation allowances, grants and scholarships to help companies focus on their creative activities. In Germany there are support programmes for start-up firms and a StartART network has been established [1].

The above mentioned concrete steps have not appeared in Romania and Georgia yet but the intention of supporting creative industries is visible among the aims of cultural policy in both countries. The strategies of several other countries refer to the need of developing suitable technics and prosperous circumstances for the evolution of creative industries. In this respect, the promotion of $R \& D$ and innovation is popular in Belgium, Finland, Lithuania, Switzerland and Sweden [1].

The Eleven Steps to Creative Finland of 2006 focussed entirely on the issues of developing creativity in a knowledge-based society and highlighted concrete steps to be taken in the field of creative industries including the reduction of the rate of unemployment and the resolution of issues related to pension, taxation and grants, etc. among others [1].

In Spain the promotion of creativity and innovation at state schools is a principal aim through teaching, specializations, competency development, cultural management and cultural institutes operating abroad. The Spanish state has also created awards (CreaArte Award) and grants (FormARte, CULTUREX) and supports civil society to promote cultural events and cultural tourism [1]

The institutional background for policies and programmes in the field of creative industries is now being developed. State institutions provide places for the representatives of the creative industries within various organizational structures. In some cases departments or directorates have been established within the ministries responsible for culture (Lithuania, Spain). Support and expert committees exist in Azerbaijan, Finland, Slovenia whereas in other countries a council operates giving advice and supervising the allocation of funds (Austria). In numerous countries creative industries receive special attention due to their potential for economic recovery, this is the case in Austria and Denmark as well where agencies are considered to be the most suitable type of institutional form for the exploitation of the economic potential of the creative sector [1].

Tony Blair established the Creative Industries Task Force in the United Kingdom as early as 1997 to measure creative industries and to develop government strategies [7]. Similarly, in 2006 the Latvian government established the consultative Design Board and the Consultative Council of Creative Industries in 2011. In Estonia a Design Centre operates, while Latvia has a Centre for Contemporary Art. In 2007, the National Association of Creative/Cultural Industries was established in Lithuania to promote the cooperation among arts, culture, artistic organisations and non-governmental organisations, businesses, the scientific and educational sector and to stimulate the activities thereof in international networks. A foundation and a working group have been established to realize the motto of the previously 
mentioned Malta Vision of 2015 ("Let our country be the country of creativity!") and to develop the necessary framework to further the above mentioned aim. In Spain the Development Agency for Cultural Industries was established by the Galician government in 2008 which promotes developments, increases competitiveness, innovation, productivity and the cooperation among national and international cultural industries, arts and performers from all regions. In Hungary the Hungarian Intellectual Property Office is responsible for the protection of intellectual property. Acting on the recommendation from the European Council, a Cultural Policy Institute operates in Russia with an active role on the international scene. A Centre for the Development of Creative Industries has been established in St. Petersburg to help non-commercial entrepreneurship within public cultural institutions operating on the "boundary between culture and business" to provide related training, consultation and expertise [7].

Most organisations perform management activities in the field of creative industries, their task is to support the sector, promote the competitiveness of public institutions and cooperation between the public and private sector. In addition, they offer planning and other services and help internationalisation.

There are several governments among the examined countries that are still working on the independence of their cultural institutional system trying to develop decentralised governance and to promote transparency with a view to efficiency which in turn have an impact on the creative industries.

Historical heritage has a great effect on cultural policy, its priorities and tools. Obviously, the protection of cultural heritage is more important in countries that boast a rich cultural heritage than in those where monuments and memorial sites are fewer in number. The protection of cultural heritage is primarily connected to tourism, thus to creative industries.

In the course of searching for projects and investigating models, it is worth examining the impacts of a certain type of historical tradition, i.e. the socialist past, since any model/regime change also has an effect on creative industry programmes.

Culture had a great importance in the socialist era since it was one of the key tools for spreading ideology, hence the high rate of state subsidy which was aimed at supporting culture in order to provide the wider society with access to cultural products and services. This era was marked by centralization, institutionalization and state monopoly, while decisions were made on a political basis using the tools of censorship and surveillance. Objectives were defined along party interests. At the same time the state maintained that classical culture or high culture and cultural institutions should be supported and established across the country. The well-established cultural network, centralized administration and regulation all guaranteed the achievement of political aims. Culture became one of the tools of propaganda in the Bolshevik type of socialism. Cultural institutions were not in need of funds therefore, the majority of society could afford the consumption of cultural products. Additionally, the fact that there were insufficient entertainment opportunities at that time and cultural industries had the greatest potential to spread information (radio, television, film, publishing etc.) also explains the above development. This high rate of cultural participation culminated in the 1980s in most countries but after the regime change it declined drastically and has not been able to reach the previous peak so far [1].

With the fall of the Soviet cultural model, post-Soviet countries experienced the immediate years after the change of system as the era of the nationalisation of their culture. They had to find and define new priorities and alter the attitude of artists to their own role since previously they had followed a defensive strategy to resist the system which restricted their freedom of creation. This attitude was not suitable to serve the newly formulated aims. The responsibility of civil society has also expanded and changed in meaning. Some of the former Socialist countries (Azerbaijan, Armenia) still have a long way to go, they need to create their own laws pertaining to culture and privatise cultural institutions or transfer them to local governments. Traditionally, the state has always been a very important owner in the field of culture (museums, archives, libraries, opera houses, etc.) but the management of cultural institutions raises a number of problems characteristic of post-Soviet countries. Although several countries have realized that they need a strategy to develop culture (Azerbaijan, Armenia), they have not yet developed it or have not yet determined the priorities of their cultural policy(Armenia, Lithuania). When the Soviet model came to an end, there was also an important change in the financing methods with the institutions receiving less and less state funds. Since culture was perceived as a crucial actor in the development process, cultural institutions were forced to look for sponsors and resort to the use of market-tools which also implied a considerable change in their traditional tasks. These changes also took place as a result of the explosive development of communication (globalization), the free choice of ideology, the increased role of the nation in culture as well as the accession or potential accession to the European Union.

\section{NeW TEChNOLOgIES AND CUltural Policies}

Novel information and communications technologies, digitalization, the network society and the entertainment possibilities offered by creative industries have transformed the traditional forms of participation in culture. By becoming part and parcel of entertainment, news also serves novel needs and demands via the Internet and smart phones.

The ongoing developments implemented in both technology and the information society contribute to the improvement of productivity and quality of life opening up not only new social and economic but also new cultural opportunities.

Digitalization has a crucial role in culture since through ensuring the preservation of and online access to cultural material, it provides for large-scale research and a more efficient exploitation of cultural goods by the wider public thus bringing about the creation of new digital content and online services. Furthermore, according to the stance of the European Council, digitalization fosters the democratization 
of access to culture and knowledge and contributes to the improvement of the information society and knowledge-based economy [8].

In its document published under the title of Digital Agenda for Europe $2010 \quad(\operatorname{COM}(2010) 245)$, the European Commission laid down its general objective aiming at establishing sustainable economic and social benefits via a single digital market that is built on a fast and ultra-fast Internet and interoperable applications [9]. The main goal of the European Digital Agenda is to make the application of information and communications technologies a key factor in successfully achieving the aims Europe has identified for 2020 [8]. The specific goals listed in the Agenda includes a call for raising digital literacy and the improvement of digital skills and proficiency [8]. The aim is to ensure that an increasing number of everyday activities is performed via the Internet and fewer and fewer citizens are excluded from these activities as a result of their social status or lack of necessary skills. Moreover, the Agenda also highlights the importance of supporting cultural diversity and creative content [8]. New digital content is especially conducive to the wide spread of cultural and creative content as it provides for cheaper and faster reproduction with authors and content-providers reaching a novel and wider (even global) public. In addition, the spread of digital cinema has been below expectations due to technical (standards) and economic (business models) reasons. Certain types of new digital cinemas are now facing closure due to the high costs of digital devices, thus their digitalization shall be supported with the aim of preserving cultural diversity. The digitalization of cultural heritage is also hindered by an excessively diverse and complicated system of authorization procedures. Finally, it is also imperative to expand the collection of the Europeana, the digital public library of the European Union [9].

Considering high priority tasks in the area of digitalization, nations in most cases refer to the digitalization of the cultural heritage preserved in museums, libraries and archives in addition to that of films.

In Austria, the Department for Media Affairs is responsible for the implementation of the European Digital Agenda launched by the European Commission in 2010 in the area of culture and arts while a separate legal provision lays down the requirement of supervising the progress made in digitalization in every second year with a particular view to the digitalization of television broadcasting. Several other offices take part in the effort to facilitate the spread of digitalization and the use of the new media in the area of arts and culture (konsortium.Netz.kultur). What is important in this respect is that they consider these activities to be a tool that contributes to a democratic, participatory and socially balanced cultural development. Poland has also revised her previous measures taken in digitalization. As a result, they outlined the Polish Programme for Digitalization in 2009 while the Polish Ministry of Culture encouraged further steps to be taken in the area of the digitalization of culture in 2010 [1].

Particular attention is paid to the digitalization of the cinema and films including specific steps and funding in Austria, Denmark, the United Kingdom, Estonia, Croatia, Hungary, Malta, Moldova, Armenia, Portugal, Spain and
Switzerland. Spain has even established a working group focusing on the sector of filmmaking and they also organized an exhibition on digital cinema in 2010 [1].

The digitalization of cultural heritage is a top priority in Denmark, Estonia, Georgia, Finland, France, Malta, Moldova, Poland, Armenia, Romania, Switzerland, Sweden, Serbia and Slovenia [1].

With regard to museums, the forerunners in digitalization include Belgium, the United Kingdom, Estonia, Finland, France, Poland, Lithuania, Norway and Portugal while regarding archives, Estonia, Finland, Latvia and Norway has been at the forefront in digitalization. France has a sharp focus on the digitalization of musical compositions [1].

A substantial amount is allocated for digitalization in Ireland where great progress has been made in the area of library collections similarly to the United Kingdom, Estonia, Finland, France, Poland, Norway, Portugal, Romania and Serbia [1].

Digital literacy is more than an individual skill, it is a characteristic of the digital system itself which creates an opportunity for establishing communication links i.e. it develops network society in addition to its favourable impact on innovation [7]. Digital proficiency is a key competence in social learning and creative competition.

The role and mode of communication has undergone a profound change to which each policy area, i.e. cultural policy as well has had to respond. The related investigation of the cultural policies of 42 countries evidenced that the states under scrutiny identify the use of new technologies and the issue of digitalization in the area of culture as priorities.

Digitalization and the use of new technologies have become a major concern since cultural heritage is an integral and crucial part of national identities which thus may be spread in the globalized world. Information and communications technologies function as bridges between culture and other sectors, bridges that reach the community as well. The progress made in digitalization is of high importance also to the creative industries since it establishes a social basis for the products of creative industries and strengthens the cultural and economic impact of creative ideas.

\section{CONCLUSION}

The definition of creative industries and the demarcation of the sector pose great difficulty and the methods used by individual nations also considerably vary, but they have one thing in common, i.e., their cultural policies do relate to creative industries in some way, although an elaborated model of creative industry policies does not exist.

At the moment, we can examine creative industry initiatives as part of cultural policies although the spread of the concept of creative industries and its presence in political documents have already affected other public policies. For example, creative industries - due to their inter-sectoral nature - have prompted cooperation between institutions in several cases, typically between ministries of culture and ministries responsible for economic growth or between ministries of education and ministries of science. This is the case in Estonia, Latvia, Spain and Sweden where special 
committees have also been established within public institutions to maintain contact with the cultural and creative industries. The growth of creative industries also have a positive effect on the ICT sectors and tourism (Malta, San Marino, Spain) [1].

The subject of cultural policies include cultural heritage, arts and - more and more frequently - the media and creative industries as well. Creative industries do not replace cultural policies, instead they draw upon them. Cultural heritage, national traditions, history, customs and the protection of the culture of (ethnic and religious) minorities are all important values. Culture creates values and cultural policies basically aim to create suitable circumstances for that process and to ensure that broad sectors of society have access to culture. The participation of society in cultural and creative activities positively affects both the public audience and the individual, the development of individuals through culture is a key priority. The creation of suitable circumstances for creative work is a fundamental need of culture. Liberty, pluralism, quality and innovation evolve in culture and through culture while they in turn contribute to the evolution of creativity. Culture is an elemental part of modern society which contributes to the intellectual and moral development of each citizen. The creative and value creating processes constitute identities, unite nations and at the same time connect nations and generations.

The role of creative industries has become increasingly appreciated in today's globalized society. Characteristically, the workers and creators of creative industries draw upon cultural roots (frequently looking for inspiration in their national culture), they need the freedom of expression, a global sphere as well as a network society to be productive. This work with its high added value, in turn, supports several other sectors (e.g. tourism), and establishes a vibrant and innovative environment that considerably affects people and their lives. This essay has researched the public policy issues related to creative industries and has found several elements that evidence that political commitment to the support of creative industries does exist.

Several countries have been paying significant attention to creative industries. Austria, the Czech Republic, Estonia, Finland, Lithuania, Macedonia, Malta, Great Britain, Portugal and Romania all have a single document about the future of creative industries, they create creative industry strategies and they have also inserted these strategies into their government programmes [1]. At the moment, the general definition of cultural and creative industries are connected to each other, and except for the above examples, most countries deal with them together instead of separating these two fields. Although the relation of cultural policies to creative industries is new, cultural policies proved to be a good starting-point for the research because they have already set concrete aims and tasks for creative industries.

According to creative industry programmes and policies, the dissemination of economic knowledge and the unfolding of entrepreneurship constitute the two primary elements of success. In addition, international relations, international presence and their subsidy are crucial parts of these programmes and policies due to the international nature of the creative industries.

The creative industry is a novel industry showing an increasing share in national economic indicators while the number and rate of employees in the creative industries are also on the increase. The aim of studying the cultural policies of 42 countries was to examine whether there is a political commitment towards creative industries and if so, to reveal its content and nature. In summary, we can conclude that dealing with creative industries is becoming increasingly institutionalized. Albeit, it would be improper to claim that each country is committed to creative industries, we can confidently state that creative industries are part of their cultural policies. In some countries their share is bigger (Austria, Denmark, Finland, France, Lithuania, Latvia, Great Britain, Norway, Spain, Sweden) and in other countries (Bulgaria, Ireland, Poland, Germany, Armenia, San Marino, Slovenia) it is smaller [1]. Creative industry strategies and programmes are being created and realized to stimulate economic and social growth and development.

\section{REFERENCES}

[1] Compendium Country Profiles. [Online]. Available: http://www.culturalpolicies.net/web/countries.php

[2] S. Gattoway and S. Dunlop, "A critique of definitions of the cultural and creative industries in public policy," International Journal of Cultural Policy, vol. 13, no. 1, 2007.

[3] PwC International Ltd: Research and Insights. (20 December 2013). [Online]. Available: http://www.pwc.com/outlook

[4] J. O'Connor: The Cultural and Creative Industries: A Review of the Literature, Arts Council England, Creative Partnerships Series, University of Leeds, pp. 1-104, 2007.

[5] The Impact of Culture on Creativity - A Study Preapared for the European Commission (Directorate-General for Education and Culture), KEA European Affairs, pp. 1-240, 2009.

[6] COM (2010) 183 green paper, "Unlocking the potential of cultural and creative industries," pp. 1-21, 2010.

[7] J. Hartley, J. Potts, S. Cunningham, T. Flew, M. Keane, and J. Banks, Key Concepts in Creative Industries, SAGE Publication Ltd., pp. 1-184, 2013.

[8] European Digital Agenda 2010 Com, vol. 245, pp. 1-42, 2010.

[9] Council Conclusions on the European Digital Library - Europeana (2008/C 319/07), pp. 1-4, 2008.

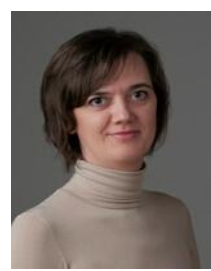

Emese Pupek is a political scientist, who acts as the president of Hungarian Educational Authority, ex-general vice-rector of BKF University of Applied Sciences, Budapest, Hungary. She is the chief editor committee of Creatio Journal and the editor in chief of books and translations, a teacher, and a researcher. Emese was the project leader of a twenty-month long research project (VIADUKT - The impact of our visual language, digital technologies and the new media on creative industries and society) supported by European Union fund.

She completed her $\mathrm{PhD}$ in Eötvös Lorand University in 2008 (innovation-interpretations, methods and European Administrative Space, Organization, management and administration theory). Emese is the author of Basics of Political Science (2009), Integration History and Public Policies of European Union (2008), Europe for Global Creativity - The Impact of European Union Initiatives on Cultural and Creative Industries (2014), Universities as Incubators of Creative Talents (2014).

She is a member of the Hungarian Political Science Association. 